\title{
Effects of Low-Dose Hydrocortisone Therapy on Immune Function in Neonatal Horses
}

\author{
KELSEY A. HART, MICHELLE H. BARTON, MICHEL L. VANDENPLAS, AND DAVID J. HURLEY \\ Department of Large Animal Medicine [K.A.H., M.H.B., M.L.V.], Department of Population Health [D.J.H.], University of Georgia, \\ Athens, Georgia 30602
}

\begin{abstract}
Low-dose hydrocortisone (LDHC) therapy modulates inflammatory responses in adults and improves outcomes in some septic adults and neonates, but its immunologic effects have not been evaluated in neonates. The objective of this study was to evaluate effects of LDHC therapy on ex vivo immune function in neonatal horses (foals). We hypothesized that LDHC treatment would dampen proinflammatory responses without impairing neutrophil function. Hydrocortisone $(1.3 \mathrm{mg} / \mathrm{kg} / \mathrm{d}$ i.v.) was administered to foals in a tapering $3.5 \mathrm{~d}$ course. Peripheral blood leukocytes were collected from foals before, during, and after hydrocortisone treatment. A separate group of age-matched untreated foals served as controls. Endotoxin-induced peripheral blood mononuclear cell gene expression of inflammatory cytokines was measured by real-time quantitative RT-PCR. Neutrophils were incubated with labeled, killed Staphylococcus aureus or Escherichia coli for assessment of phagocytosis, and with phorbol myristate acetate, zymosan, or endotoxin for measurement of reactive oxygen species (ROS) production. Neutrophil phagocytosis and ROS production were similar in both groups. Foals receiving hydrocortisone had significantly decreased endotoxininduced expression of TNF- $\alpha$, IL-6, IL-8, and IL-1 $\beta$. These data suggest that this LDHC treatment regimen ameliorates endotoxininduced proinflammatory cytokine expression in neonatal foals without impairing innate immune responses needed to combat bacterial infection. (Pediatr Res 70: 72-77, 2011)
\end{abstract}

$\mathrm{C}$ ortisol is vital for the stress response to critical illness and plays an essential role in regulation of the inflammatory response (1). In some patients, though, the cortisol response to illness is inadequate, and a condition called relative adrenal insufficiency (RAI) or critical illness-related corticosteroid insufficiency (CIRCI) (2-4) arises. The physiologic consequences of RAI/CIRCI can include cardiovascular collapse and an excessive, unregulated systemic inflammatory response $(3,4)$. A number of studies have documented a significantly higher incidence of multiple organ failure and death in septic patients with RAI/CIRCI compared with patients with intact hypothalamic-pituitary-adrenal (HPA) axis function (4-6). An exaggerated systemic inflammatory response characterized by imbalance in pro- and anti-inflammatory cytokine production is also documented in septic people and animals and is

Received September 7, 2010; accepted January 12, 2011.

Correspondence: Kelsey A. Hart, D.V.M., Ph.D., Department of Large Animal Medicine, 501 DW Brooks Drive, University of Georgia College of Veterinary Medicine, Athens, GA 30605; e-mail: khart4@uga.edu

Supported by grants from the National Institutes of Health (GM086003), the Grayson Jockey Club Research Foundation, and the American Quarter Horse Foundation.

Portions of this work were presented in abstract form at the American College of Veterinary Internal Medicine Annual Forum, Anaheim, California, June 9-12, 2010. also predictive of increased disease severity and death $(1,7-$ 12). Cortisol insufficiency during sepsis is theorized to contribute to such an overwhelming inflammatory response $(1,10,12)$.

Thus, glucocorticoids have been administered to septic patients in varying doses in attempts to quell inflammation. Although high-dose corticosteroid therapy is associated with adverse effects and decreased survival in septic patients (13-15), a number of studies have described improved shock reversal and survival in septic patients with RAI/CIRCI when supplemented with low-dose hydrocortisone (LDHC) (4,13-17).

As fetal HPA axis function does not mature until the peripartum period, cortisol insufficiency may be of particular significance in the neonate $(3,18)$. A number of studies have documented cortisol insufficiency in septic adult and pediatric patients and in critically ill full-term and preterm infants $(4,6,19-22)$. However, to the authors' knowledge, the effects of LDHC therapy on immune function in neonates of any species are not described. Given the numerous differences in endocrine and immune function and in hydrocortisone pharmacokinetics between adults and neonates $(3,18,23)$, specific evaluation of LDHC therapy in the neonate is critical to optimize therapeutic recommendations for this population.

Like infants, neonatal horses (foals) exhibit substantial HPA axis immaturity in the perinatal period (24-27) and are highly susceptible to the development of bacterial sepsis (28). In addition, naturally occurring RAI/CIRCI is described in $\sim 40 \%$ of septic neonatal foals and is correlated with increased incidence of shock, multiple organ failure, and death (29), as documented in septic adults, children, and infants $(4,6,19$ 22). Furthermore, septic foals also exhibit similar inflammatory dysregulation to septic infants, characterized by increased expression of proinflammatory cytokine genes such as TNF- $\alpha$ and IL-6 (7,8,30).

Thus, the primary objective of this study was to examine the effects of LDHC therapy on measures of immune function in neonatal foals in an ex vivo model. In addition, effects of LDHC therapy on HPA axis function were examined. We hypothesized that LDHC treatment 1) would not significantly impair the ability of peripheral blood granulocytes to produce

Abbreviations: CIRCI, critical illness-related corticosteroid insufficiency; HPA, hypothalamic-pituitary-adrenal; LDHC, low-dose hydrocortisone; PBMC, peripheral blood mononuclear cell; PMA, phorbol myristate acetate; RAI, relative adrenal insufficiency; ROS, reactive oxygen species 
reactive oxygen species (ROS) or phagocytose bacteria; 2) would significantly decrease endotoxin-induced expression of proinflammatory cytokine genes and significantly increase endotoxin-induced expression of anti-inflammatory cytokine genes in peripheral blood mononuclear cells (PBMCs); and 3) would not significantly suppress HPA axis function in vivo after discontinuation of hydrocortisone administration.

\section{MATERIALS AND METHODS}

Animals. Thirty-nine healthy 2- to 7-d-old full-term foals (GA $\geq 330 \mathrm{~d}$, weight $40-60 \mathrm{~kg}$ ) from university research herds were used. Foals were housed with the dam and were determined to be healthy during the study period by daily physical examination. Eleven foals (four females and seven males) were treated with LDHC (hydro group), and 28 age-matched foals (15 females and 13 males) were untreated (control group). Seventeen control foals were used to provide age-matched comparisons with hydro foals for immune function testing, and 11 control foals provided age-matched HPA axis function comparisons with hydro foals. Group assignments were randomized by order of foaling and were known to the investigators.

Study methods were approved by the University of Georgia's and Clemson University's Institutional Animal Care and Use Committee, and mare/foal pairs were cared for according to the guidelines stated in an Animal Use Protocol determined and approved by each university's Department of Animal Resources.

LDHC treatment and sampling protocol. Sampling protocols for hydro and control foals are shown in Figure 1. Between 36 and $60 \mathrm{~h}$ of age, all hydro foals had an i.v. jugular catheter placed under brief standing restraint. Beginning 12 to $18 \mathrm{~h}$ after catheter placement, hydro foals received a tapering $3.5 \mathrm{~d}$ course of hydrocortisone sodium succinate (Pfizer, NY, NY) as follows: $1.3 \mathrm{mg} / \mathrm{kg} / \mathrm{d}$ for $48 \mathrm{~h}, 0.65 \mathrm{mg} / \mathrm{kg} / \mathrm{d}$ for $24 \mathrm{~h}$, and $0.33 \mathrm{mg} / \mathrm{kg} / \mathrm{d}$ for $12 \mathrm{~h}$. This total daily dose was determined by multiplying the daily endogenous cortisol production rate in healthy neonatal foals (31) by a factor of 2 to approximate an appropriate cortisol response to stress as described in other species $(2,32,33)$. This total daily dose was divided into six doses administered as an i.v. bolus every $4 \mathrm{~h}$.

Sixty-five milliliters of blood was collected just before the first dose of hydrocortisone (pretreatment), after $48 \mathrm{~h}$ of therapy before the initial dose was halved (during-treatment), and $12 \mathrm{~h}$ after cessation of hydrocortisone administration (posttreatment). Five milliliters of blood was allowed to clot, centrifuged, and serum stored at $-80^{\circ} \mathrm{C}$ until analysis for cortisol/hydrocortisone concentrations. The remaining $60 \mathrm{~mL}$ was anticoagulated with $2 \mathrm{~mL} 100 \mu \mathrm{M}$ EDTA for isolation of peripheral blood leukocytes. At the during-treatment sample, blood was also collected $5 \mathrm{~min}$ after hydrocortisone administration for measurement of peak serum hydrocortisone concentration.

In the 17 control foals used for immune function comparisons, blood was collected similarly on d 2, d 4, and d 6 of life to permit age-matched comparisons with the hydro group. Twenty-four hours after discontinuation of hydrocortisone therapy, posttreatment HPA axis function and responsiveness was assessed in 8 of 11 hydro foals. Blood was collected for measurement of basal cortisol concentrations and a paired low-dose $(10 \mu \mathrm{g}) /$ high-dose $(100$ $\mu \mathrm{g}$ ) cosyntropin (synthetic ACTH, $\alpha$ 1-24 corticotropin; Amphastar Pharmaceuticals, Rancho Cucamonga, CA) stimulation test (24) was performed (Fig. 2). Ten micrograms cosyntropin, rather than the standard $1 \mu \mathrm{g}$ dose used in people, was used for the low-dose cosyntropin stimulation test because lack of a measurable cortisol response to $1 \mu \mathrm{g}$ cosyntropin in neonatal foals has been previously demonstrated (34).

In the 11 control foals used for HPA axis function comparisons, blood was collected on d 2 and between d 5 and 7 of age for measurement of basal cortisol concentrations for comparisons with hydro foals. A paired cosyntropin stimulation test was also performed between d 5 and 7 of age in these control foals for comparison with hydro foals' posttreatment cosyntropin stimulation responses. Some findings in this group have been published previously (24).

Cortisol and hydrocortisone assays. Serum total cortisol and hydrocortisone concentrations were determined on an automated analyzer using a chemiluminescent immunoassay (Immulite, Diagnostics Product Corporation, Los Angeles, CA) validated for use in the horse $(35,36)$.

Ex vivo immune function testing. Peripheral blood granulocytes and PBMCs were isolated within $120 \mathrm{~min}$ of collection by density-gradient centrifugation over Histopaque-1077 (Sigma Chemical Co.-Aldrich, St. Louis, MO) as previously described $(37,38)$. Viability of both cell types was greater than $95 \%$ as assessed by trypan blue exclusion.

Neutrophil ROS production in response to endotoxin $(100 \mathrm{ng} / \mathrm{mL} ; E s c h$ erichia coli 055:B5 LPS; List Biological Inc., Campbell, CA), zymosan (1000 $\mathrm{ng} / \mathrm{mL}$; Molecular Probes, Eugene, OR), and phorbol myristate acetate (PMA, $10^{-7} \mathrm{M}$; Molecular Probes, Eugene, OR) was measured using a fluorometric assay as previously described (37). Assessment of ROS production in response to these three stimulants permitted assessment of the cells' toll-like receptor 4 (TLR-4)-mediated ROS production (endotoxin), dectin-1-mediated ROS production (zymosan), and overall capacity to produce ROS in response to protein kinase $\mathrm{C}$ activation (PMA).

To determine phagocytic function, isolated neutrophils were resuspended to a final concentration of $3 \times 10^{6}$ cells $/ \mathrm{mL}$ in RPMI 1640 without phenol red supplemented with $50 \mu \mathrm{g}$ gentamicin sulfate, $2 \mathrm{mM}$ L-glutamine, $1 \mathrm{mM}$ sodium pyruvate, and $10 \%$ heat-inactivated fetal bovine serum (Hyclone, Logan, UT). Bodipy-labeled, inactivated E. coli and Staphylococcus aureus (Invitrogen, Carlsbad, CA) were diluted to a final concentration of $2 \times$ $10^{6} / \mathrm{mL}$. Two hundred microliters of resuspended cells were incubated in duplicate with $50 \mu \mathrm{L} E$. coli or S. aureus or with media only for $60 \mathrm{~min}$ at $37^{\circ} \mathrm{C}$ and $5 \% \mathrm{CO}_{2}$. Cells were then washed with FACS buffer and fixed in $1 \%$ formalin. Flow cytometric analysis was conducted within $7 \mathrm{~d}$ of fixation (Accuri C6 Cytometer; Accuri Cytometers Inc., Ann Arbor, MI). Extracellular bacterial fluorescence was quenched with $0.4 \%$ trypan blue (Sigma Chemical Co. Chemical, St. Louis, MO), and samples were then assessed for the percent of fluorescent-positive cells using commercial software (CFlowPlus; Accuri Cytometers Inc., Ann Arbor, MI).

After isolation, PBMCs were resuspended in RPMI 1640 supplemented with $100 \mathrm{IU} / \mathrm{mL}$ penicillin, $100 \mathrm{mg} / \mathrm{mL}$ streptomycin, and $10 \%$ equine serum (Hyclone, Logan, UT). The cells were equally divided among six sterile $60 \times$ $15 \mathrm{~mm}$ petri dishes and incubated for $30 \mathrm{~min}$ at $37^{\circ} \mathrm{C}$ in $5 \% \mathrm{CO}_{2}$. Plates were then treated with $1 \mathrm{ng} / \mathrm{mL}$ endotoxin (E. coli 011:B4 LPS; List Biological Inc., Campbell, CA) or an equivalent volume of media and incubated at $37^{\circ} \mathrm{C}$

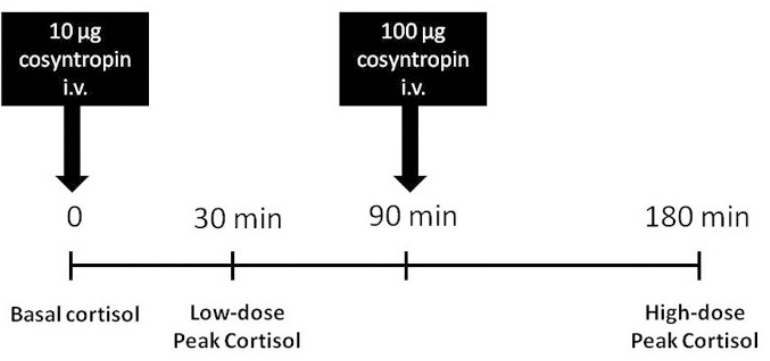

Figure 2. Paired low-dose/high-dose cosyntropin stimulation test design. At time 0 , blood was collected for measurement of basal cortisol concentration, followed by administration of $10 \mu \mathrm{g}$ cosyntropin i.v. Blood was collected 30 min later to assess the cortisol response to $10 \mu \mathrm{g}$ cosyntropin (low-dose peak cortisol). At $90 \mathrm{~min}, 100 \mu \mathrm{g}$ cosyntropin was administered i.v., and blood was collected $90 \mathrm{~min}$ later to assess the cortisol response to $100 \mu \mathrm{g}$ cosyntropin (high-dose peak cortisol).

Figure 1. Foal groups and sampling protocols. *Control foals used for HPA axis function comparisons with hydro foals were sampled on $\mathrm{d} 2$ of age and once between d 5 and 7 of age. 
and $5 \% \mathrm{CO}_{2}$ for 1,4 , and $20 \mathrm{~h}$. Cells were scraped from the plates in cold PBS, pelleted via brief centrifugation at $14,000 \times \mathrm{g}$, and lysed with RNA cell lysis solution (Qiagen, Valencia, CA) in combination with $10 \mu \mathrm{L} / \mathrm{mL} 2$-mercaptoethanol (Sigma Chemical Co. Chemical, St. Louis, MO) and stored at $-80^{\circ} \mathrm{C}$ until RNA extraction. Total RNA was extracted from cell lysates using the RNeasy mini RNA extraction kit (Qiagen, Valencia, CA) according to the manufacturer's protocol and treated with DNase I at $25^{\circ} \mathrm{C}$ for $30 \mathrm{~min}$. Only samples having 260:280 nm absorbance ratios between 2.0 and 2.2 as measured on a NanoDrop spectrophotometer (ThermoFisher Scientific, Wilmington, DE) were processed for cDNA synthesis with the High Capacity cDNA Archive Kit (Applied Biosystems, Foster City, CA) using 500 ng RNA as template.

Expression of TLR-4, TNF- $\alpha$, IL-1 $\beta$, IL-6, IL-10, IL-4, IL-8, and TGF- $\beta$ were quantified using validated two-step real-time quantitative RT-PCR assays with SYBR Green detection in an Applied Biosystems 7900HT sequence detection system (Foster City, CA), with 18S ribosomal RNA used as an endogenous housekeeping control as previously reported $(39,40)$. Changes in gene expression were calculated by relative quantification against 18s rRNA using the $\Delta \Delta \mathrm{C}_{\mathrm{T}}$ method with plain media controls used as the calibrator. Fold changes in gene expression between endotoxin-stimulated and unstimulated cells from the same foal for each incubation period $(1,4$, and $20 \mathrm{~h}$ ) at each sampling time point were calculated as $2^{-\Delta \Delta \mathrm{CT}}$.

Data analysis. Between-group comparisons between age-matched hydro and control foals were conducted using $t$ tests for parametrically distributed data and Mann Whitney $U$ tests for nonparametric data, after normality was assessed with the Kolmogorov-Smirnov test. For inflammatory mediator gene expression, lipopolysaccharide-induced fold changes in gene expression

Table 1. Neutrophil ROS production in hydro foals before, during, and after hydrocortisone treatment and in age-matched control

foals after ex vivo stimulation with endotoxin $(100 \mathrm{ng} / \mathrm{mL})$, zymosan $(100 \mathrm{ng} / \mathrm{mL})$, and PMA $\left(10^{-7} \mathrm{M}\right)$

\begin{tabular}{cccc}
\hline & Pretreatment & $\begin{array}{c}\text { During } \\
\text { treatment }\end{array}$ & Posttreatment \\
\hline & Response to endotoxin (corrected AFUs) \\
\hline Hydro foals & $6.4 \pm 4.6$ & $4.2 \pm 5.9$ & $4.3 \pm 5.7$ \\
$(n=11)$ & $(0.4$ to 15.1$)$ & $(-1.7$ to 18.2$)$ & $(-1.9$ to 16.6$)$ \\
Control foals & $2.9 \pm 4.1$ & $0.7 \pm 5.0$ & $0.4 \pm 3.3$ \\
$(n=13)$ & $(-2.7$ to 10.6$)$ & $(-6.4$ to 7.4$)$ & $(-4.7$ to 4.9$)$
\end{tabular}

Response to zymosan (corrected AFUs)

\begin{tabular}{cccc}
\hline Hydro foals & $16.2 \pm 3.0$ & $15.8 \pm 9.8$ & $19.5 \pm 17.8$ \\
$(n=11)$ & $(9.1$ to 19.4$)$ & $(-3.3$ to 33.7$)$ & $(-3.7$ to 56.3$)$ \\
Control foals & $13.7 \pm 7.2$ & $9.3 \pm 5.9$ & $11.3 \pm 2.9$ \\
$(n=13)$ & $(2.3$ to 25.8$)$ & $(0.4$ to 18.9$)$ & $(8.3$ to 18.0$)$ \\
\multicolumn{4}{c}{} \\
& Response to PMA (corrected AFUs) \\
\hline Hydro foals & $51.6 \pm 16.2$ & $71.2 \pm 22.8$ & $100.6 \pm 57.9$ \\
$(n=11)$ & $(29.8$ to 75.3$)$ & $(43.7$ to 16.8$)$ & $(41.5-227.4)$ \\
Control foals & $65.2 \pm 17.4$ & $71.6 \pm 21.9$ & $89.6 \pm 34.7$ \\
$(n=13)$ & $(41.2$ to 93.1$)$ & $(40.0-110.6)$ & $(45.5-176.6)$ \\
\hline
\end{tabular}

ROS production is expressed as corrected arbitrary fluorescence units (AFUs), which were calculated by subtracting background fluorescence in unstimulated control cells from fluorescence in stimulated cells. Data are expressed as mean $\pm \mathrm{SD}$ (range). No significant differences $(p<0.05)$ were found between hydro and control foals. $\leq 3$-fold were not considered relevant gene induction. Thus, if both control and hydro foals failed to exhibit an endotoxin-induced change in expression of $>3$-fold for a specific gene, further between-group comparisons for that gene at that day and incubation time point were not conducted. Statistical analysis was performed using commercial statistical software (Prism Version 4; GraphPad Software, Inc., San Diego, CA) and statistical significance was set at $p<0.05$.

\section{RESULTS}

No severe adverse effects were noted in any hydro foals. Two foals developed a partial thrombus at the jugular catheter site during treatment and one foal developed mild diarrhea $72 \mathrm{~h}$ into hydrocortisone treatment, all of which resolved without specific therapy.

ROS production. Neutrophil ROS production in response to endotoxin, zymosan, and PMA in hydro and control foals is shown in Table 1. No significant differences in ROS production in response to any stimulants were found between hydro and control foals before, during, or after hydrocortisone treatment.

Phagocytic function. Neutrophil phagocytosis of E. coli and $S$. aureus in hydro and control foals is shown in Table 2. No significant differences in phagocytic function were found between hydro and control foals before, during, or after hydrocortisone treatment.

Inflammatory molecule gene expression. Both hydro and control foals exhibited a $>3$-fold endotoxin-induced change in gene expression for TNF- $\alpha$, IL-6, IL-1 $\beta$, IL-8, and IL-10 for at least one incubation time on each sampling day, permitting between-group comparisons. Endotoxin-induced changes in gene expression for TLR-4, IL-4, and TGF- $\beta$ were $<3$-fold for both groups and at all incubation times on all sampling days, so between-group analysis was not conducted for these genes.

No significant differences in endotoxin-induced gene expression were found between hydro and control foals at the pretreatment sample for any genes except IL-8, for which hydro foals had significantly lower expression than control foals $(p=0.027)$ after $4 \mathrm{~h}$ of incubation with endotoxin.

Endotoxin-induced changes in gene expression for TNF- $\alpha$, IL-6, IL-1 $\beta$, IL-8, and IL-10 in hydro foals during and after hydrocortisone treatment and in age-matched CONTROL foals are shown in Figure 3. At the during-treatment sample, hydro foals exhibited significantly lower endotoxin-induced expression of IL-6 $(p<0.001)$, IL-1 $\beta(p<0.036)$, and IL-8 ( $p=0.004$ to $p=0.019)$ than control foals. In addition, hydro foals also exhibited lower expression of IL- $1 \beta$ and IL-10 after $4 \mathrm{~h}$ of endotoxin incubation that approached statistical significance ( $p=0.053$ and $p=0.050$, respectively).

At the posttreatment sample, endotoxin-induced expression of IL-6 ( $p=0.023)$, IL-1 $\beta(p<0.001$ to $p=0.021)$, and IL-8

Table 2. Phagocytosis of killed, bodipy-labeled E. coli and S. aureus by isolated neuotrophils from hydro foals before, during, and after hydrocortisone treatment and from age-matched control foals

\begin{tabular}{|c|c|c|c|c|c|c|}
\hline & \multicolumn{3}{|c|}{ Phagocytosis of E. coli (\% positive cells) } & \multicolumn{3}{|c|}{ Phagocytosis of S. aureus (\% positive cells) } \\
\hline & Pretreatment & During treatment & Posttreatment & Pretreatment & During treatment & Posttreatment \\
\hline $\begin{array}{l}\text { Hydro foals } \\
(n=11)\end{array}$ & $16.7 \pm 13.2(2.0-44.6)$ & $19.4 \pm 12.7(3.3-38.2)$ & $16.7 \pm 10.6(0.0-33.5)$ & $22.0 \pm 9.2(5.0-34.8)$ & $17.6 \pm 8.9(6.3-34.0)$ & $19.2 \pm 11.1(5.2-46.8)$ \\
\hline $\begin{array}{l}\text { Control foals } \\
\quad(n=9)\end{array}$ & $11.9 \pm 9.9(1.0-28.2)$ & $14.3 \pm 13.9(2.7-45.1)$ & $11.8 \pm 8.3(1.5-22.3)$ & $19.6 \pm 14.0(1.3-41.3)$ & $14.9 \pm 10.4(6.2-39.8)$ & $11.1 \pm 6.8(2.2-22.3)$ \\
\hline
\end{tabular}

Phagocytosis is expressed as \% positive cells detected by flow cytometry after quenching of extracellular fluorescence with $0.4 \%$ trypan blue. Data are expressed as mean $\pm \mathrm{SD}$ (range). No significant differences $(p<0.05)$ were found between hydro and control foals. 
A

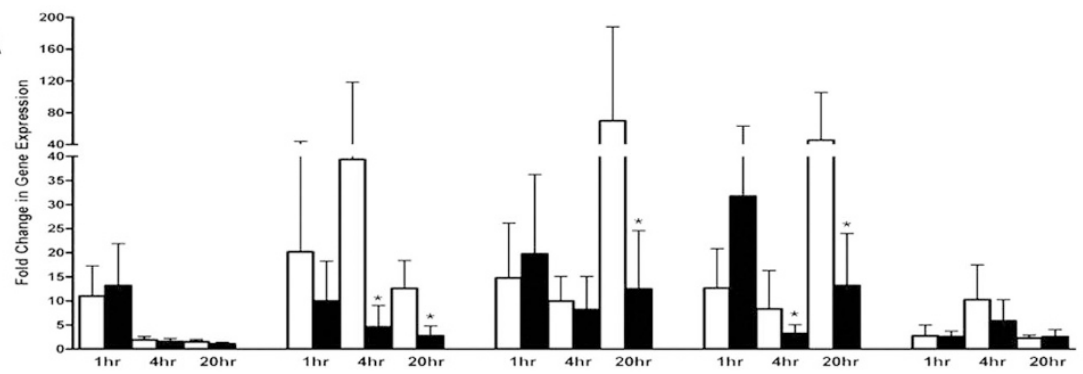

B

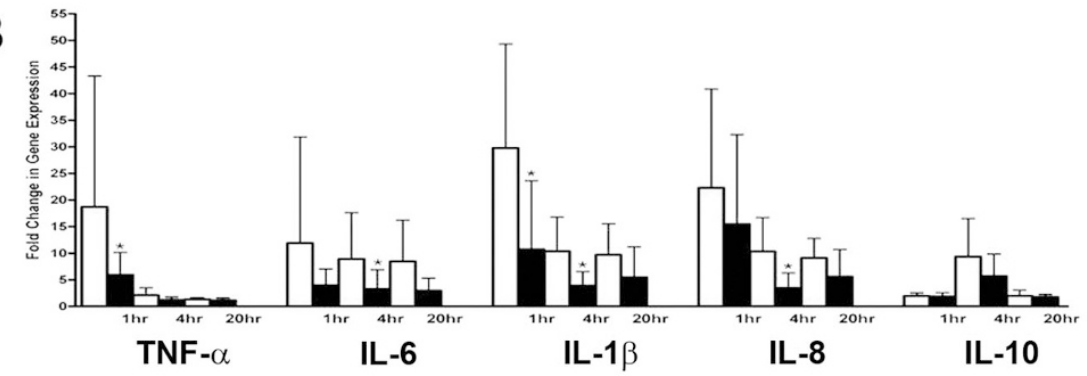

Figure 3. Mean fold change in mRNA expression of TNF- $\alpha$, IL-6, IL- $1 \beta$, IL-8, and IL-10 in PBMCs from hydro foals $(n=11 ; \mathbf{\square})$ and age-matched control foals $(n=15 ; \square)$ incubated with endotoxin $(1 \mathrm{ng} / \mathrm{mL})$ for 1,4 , and $20 \mathrm{~h}$. Fold change in mRNA expression is relative to unstimulated PBMCs from the same animal. Expression during and after hydrocortisone treatment is shown in $(A)$ and $(B)$, respectively. $*$ Significant $(p<0.05)$ difference between hydro and control foals.

Table 3. Serum cortisol/hydrocortisone concentrations in hydro and age-matched control foals before, during, and after low-dose hydrocortisone treatment

\begin{tabular}{|c|c|c|c|c|}
\hline & \multirow{2}{*}{$\begin{array}{c}\text { Serum cortisol/hydrocortisone* } \\
\text { concentration }(\mu \mathrm{g} / \mathrm{dL}) \text { pretreatment } \\
\text { (day } 2 \text { of age })\end{array}$} & \multicolumn{2}{|c|}{$\begin{array}{l}\text { Serum cortisol/hydrocortisone* concentration } \\
(\mu \mathrm{g} / \mathrm{dL}) \text { during treatment } \dagger \text { (day } 4 \text { of age) }\end{array}$} & \multirow{2}{*}{$\begin{array}{c}\text { Serum cortisol/hydrocortisone* } \\
\text { concentration }(\mu \mathrm{g} / \mathrm{dL}) \text { posttreatment } \\
(\text { day } 6 \text { of age })\end{array}$} \\
\hline & & Trough & Peak & \\
\hline Hydro foals $(n=11)$ & $2.6 \pm 1.0(1.6-4.7)$ & $2.1 \pm 1.4(0.4-4.9)$ & $22.3 \pm 9.5(15.0-44.9)$ & $2.5 \pm 1.0(1.2-4.6)$ \\
\hline Control foals $(n=11)$ & $2.4 \pm 1.0(1.3-4.4)$ & $\mathrm{n} / \mathrm{a}$ & $\mathrm{n} / \mathrm{a}$ & $2.0 \pm 0.8(1.0-3.6)$ \\
\hline
\end{tabular}

Data were expressed as mean \pm SD (range). No significant differences $(p<0.05)$ were found between hydro and control foals.

* Cortisol and hydrocortisone are chemically indistinguishable.

$\dagger$ Samples for trough and peak cortisol/hydrocortisone concentrations during treatment were collected immediately before and 5 min after i.v. bolus administration of hydrocortisone, respectively.

Table 4. Basal serum cortisol concentrations and serum cortisol responses to a paired low-dose (10 $\mu \mathrm{g}) / \mathrm{high}$-dose (100 $\mu \mathrm{g})$ cosyntropin stimulation test in hydro and age-matched control foals

\begin{tabular}{lccccc}
\hline & $\begin{array}{c}\text { Basal cortisol } \\
(\mu \mathrm{g} / \mathrm{dL})\end{array}$ & $\begin{array}{c}\text { Low-dose peak* } \\
\text { cortisol }(\mu \mathrm{g} / \mathrm{dL})\end{array}$ & $\begin{array}{c}\text { High-dose peak } \dagger \\
\text { cortisol }(\mu \mathrm{g} / \mathrm{dL})\end{array}$ & $\begin{array}{c}\text { Low-dose delta } \neq \\
\text { cortisol }(\mu \mathrm{g} / \mathrm{dL})\end{array}$ & $\begin{array}{c}\text { High-dose delta } \$ \\
\text { cortisol }(\mu \mathrm{g} / \mathrm{dL})\end{array}$ \\
\hline Hydro foals $(n=8)$ & $1.8 \pm 0.9(0.7-3.6)$ & $3.1 \pm 1.0(1.9-4.6)$ & $5.0 \pm 1.7(3.4-7.9)$ & $1.4 \pm 0.7(0.6-2.8)$ & $3.2 \pm 1.4(1.8-6.1)$ \\
Control foals $(n=11)$ & $2.0 \pm 0.8(1.0-3.6)$ & $3.3 \pm 0.8(2.3-4.4)$ & $5.5 \pm 1.1(3.5-7.4)$ & $1.3 \pm 0.6(0.6-2.6)$ & $3.5 \pm 1.3(1.7-5.9)$ \\
\hline
\end{tabular}

Data were expressed as mean \pm SD (range). No significant differences $(p<0.05)$ were found between hydro and control foals.

* Low-dose peak cortisol concentrations were obtained $30 \mathrm{~min}$ after i.v. administration of $10 \mu \mathrm{g}$ cosyntropin.

$\dagger$ High-dose peak cortisol concentrations were obtained 90 min after i.v. administration of $100 \mu \mathrm{g}$ cosyntropin.

\$ Delta cortisol concentrations were calculated by subtracting the basal cortisol concentration from the peak cortisol concentration reached after administration of $10 \mu \mathrm{g}$ (low-dose delta cortisol) or $100 \mu \mathrm{g}$ cosyntropin (high-dose delta cortisol).

$(p=0.002)$ remained significantly lower in hydro foals than control foals. Endotoxin-induced expression of TNF- $\alpha$ was also significantly lower in hydro foals $(p=0.047)$ at this sample. Endotoxin-induced expression of IL- $1 \beta$ and IL- 8 after $20 \mathrm{~h}$ of incubation also was lower in hydro foals and approached statistical significance $(p=0.054$ and $p=0.054$, respectively).

Serum cortisol and hydrocortisone concentrations. Serum cortisol and hydrocortisone concentrations in hydro foals before, during, and after LDHC treatment are shown in Table 3. Paired cosyntropin stimulation test results in hydro and control foals are shown in Table 4. There were no significant differences between hydro and age-matched control foals in HPA axis function as assessed by basal cortisol concentration before or after hydrocortisone treatment, or by peak or delta cortisol (peak - basal cortisol) responses to low- (10 $\mu \mathrm{g})$ or high- (100 $\mu \mathrm{g})$ dose cosyntropin after hydrocortisone treatment.

\section{DISCUSSION}

The results herein provide support for our hypotheses and illustrate that LDHC dampens the proinflammatory cytokine response to ex vivo endotoxin exposure without significantly suppressing neutrophil function in neonatal foals. Furthermore, HPA axis function after discontinuation of LDHC treatment was not significantly suppressed in hydro foals. In sum, these findings suggest that a similar LDHC regimen may ameliorate a detrimental proinflammatory response in septic 
neonates without impairing innate immune and endocrine responses to the inciting infection.

The finding that LDHC did not impair ROS production or phagocytic function in isolated foal neutrophils is consistent with previous reports from adult animals and humans (41-43). The results herein support these previous studies and suggest that innate immune mechanisms also remain intact in neonates receiving LDHC.

The significant reduction in endotoxin-induced gene expression of the proinflammatory cytokines TNF- $\alpha$, IL-6, IL$1 \beta$, and IL- 8 in hydro foals was also consistent with previous reports of decreased proinflammatory mediators in septic adult humans receiving LDHC (32,42-44). However, to the authors' knowledge, this is the first study to show persistence of anti-inflammatory effects after discontinuation of hydrocortisone therapy, as evidenced by a significant decrease in TNF- $\alpha$, IL-6, and IL- $1 \beta$ expression in hydro foals $12 \mathrm{~h}$ after discontinuation of hydrocortisone. As transcriptional effects of corticosteroids can involve modification of regulatory molecule production, it is not surprising that some functional genomic effects might persist after steroid administration ceases. Although further study is needed, a short course of LDHC may also result in prolonged anti-inflammatory effects in clinical patients.

Although increased expression of the anti-inflammatory cytokines TGF- $\beta$ and IL- 4 was expected in hydro foals, a relevant $>3$-fold endotoxin-induced change in expression was not observed for these genes, and no further between-group comparisons were possible. Expression of these cytokines may not be induced until later in the inflammatory response, and differences might have been observed if longer endotoxin exposure was conducted. Alternatively, it is possible that expression of TGF- $\beta$ and IL-4 is not regulated via TLR-4mediated pathways in foal PBMCs.

Expression of the anti-inflammatory cytokine IL-10 was significantly increased after endotoxin exposure in comparison with unstimulated cells in both groups of foals, but expression in hydro foals was comparable to control foals. Corticosteroid treatment has been shown to increase production of IL-10 from isolated human PBMCs (10), but other studies have documented suppression of IL-10 production with LDHC therapy in septic adult humans (42). These contradictory effects may reflect temporal changes in cytokine production related to the duration of the inflammatory response in clinical sepsis versus experimental models. Furthermore, as this study examined IL-10 gene expression rather than protein production, posttranscriptional changes in IL-10 production may have been missed.

It is important to note that the LDHC regime used in this study used a lower daily dose and shorter course of therapy than current recommendations in septic adult humans (16). The hydrocortisone dose and q. $4 \mathrm{~h}$ dosing protocol used in our study was based on daily endogenous cortisol production rates and secretion patterns in healthy foals (31) and was derived similarly to LDHC recommendations in adult humans $(2,32,33)$. This hydrocortisone regimen did suppress proinflammatory responses in leukocytes from healthy foals to a degree comparable with that achieved with higher doses in septic and endotoxemic adult animals and people $(10,32,41,42)$. A similar daily hydrocortisone dose of 1 to 2 $\mathrm{mg} / \mathrm{kg}$ divided into intermittent boluses has been recently recommended for use in human neonates with CIRCI (3). The appropriate duration of hydrocortisone treatment in both neonates and adults, however, remains unclear and is best governed by the underlying disease process being managed (i.e. septic shock versus prematurity) and the clinical response of the individual patient. A shorter LDHC course than the standard 7-d protocol (16) was evaluated here because the authors questioned whether shorter treatment duration would provide still adequate anti-inflammatory effects and thus might have potential clinical utility in patients (such as neonates) in which adverse effects of steroid treatment are particularly undesirable. Further study to evaluate the effects of shorter-duration LDHC regimens in adults and neonates in a clinical setting is needed.

An important limitation of this study is the use of an ex vivo model of infection with cells obtained from a small number of healthy animals. Infection in the live animal or person stimulates complex host-pathogen interactions with important endocrine and immunological consequences that could impact the response to LDHC in clinical patients. For instance, the inflammatory response in naturally occurring sepsis is likely present for a longer duration and to a greater degree than in this experimental model, so altered steroid dosing might be required in clinical patients. The anti-inflammatory effects of the LDHC protocol used in this report must be confirmed in larger scale in vivo studies with experimental and naturally occurring infection.

In conclusion, the LDHC therapy protocol used in the study herein dampened the ex vivo proinflammatory response to endotoxin in neonatal foals without significantly impairing $e x$ vivo neutrophil function or endogenous HPA axis activity. These anti-inflammatory effects occurred with a lower dose and shorter course than is currently recommended in adults with RAI/CIRCI, and some anti-inflammatory effects persisted after discontinuation of hydrocortisone. Further study is needed to evaluate the immunologic and clinical effects of a similar protocol in clinical patients.

Acknowledgments. We thank Lorelei Jones, Kari Anderson, Dr. Gary Heusner, Dr. Greg Queen, and the students who assisted with sampling; Londa Berghaus, Shay Bush, Kate Hurley, Natalie Norton, Denise Pope, and Caroline Salter for technical assistance; and Dr. Roy Berghaus for statistical consultation.

\section{REFERENCES}

1. Marik PE 2007 Mechanisms and clinical consequences of critical illness associated adrenal insufficiency. Curr Opin Crit Care 13:363-369

2. Aneja R, Carcillo J 2007 What is the rationale for hydrocortisone treatment in children with infection-related adrenal insufficiency and septic shock. Arch Dis Child 92:165-169

3. Fernandez EF, Watterberg KL 2009 Relative adrenal insufficiency in the preterm and term infant. J Perinatol 29:S44-S49

4. Marik PE 2009 Critical illness-related corticosteroid insufficiency. Chest 135:181193

5. Annane D, Maxime V, Ibrahim F, Alvarez J, Abe E, Boudou P 2006 Diagnosis of adrenal insufficiency in severe sepsis and septic shock. Am J Respir Crit Care Med 174:1319-1326 
6. Pizarro CF, Troster EJ, Damiani D, Carcillo JA 2005 Absolute and relative adrenal insufficiency in children with septic shock. Crit Care Med 33:855-859

7. Gold JR, Perkins GA, Erb HN, Ainsworth DM 2007 Cytokine profiles of peripheral blood mononuclear cells isolated from septic and healthy neonatal foals. J Vet Intern Med 21:482-488

8. Harris MC, D'Angio CT, Gallagher PR, Kaufman D, Evans J, Kilpatrick L 2005 Cytokine elaboration in critically ill infants with bacterial sepsis, necrotizing enterocolitis, or sepsis syndrome: correlation with clinical parameters of inflammation and mortality. J Pediatr 147:462-468

9. Wang H, Ma S 2008 The cytokine storm and factors determining the sequence and severity of organ dysfunction in multiple organ dysfunction syndrome. Am J Emerg Med 26:711-715

10. Haddad JJ, Saadé NE, Safieh-Garabedian B 2002 Cytokines and neuro-immuneendocrine interactions: a role for the hypothalamic-pituitary-adrenal revolving axis. J Neuroimmunol 133:1-19

11. Ng PC, Li K, Wong RP, Chui K, Wong E, Li G, Fok TF 2003 Proinflammatory and anti-inflammatory cytokine responses in preterm infants with systemic infections. Arch Dis Child Fetal Neonatal Ed 88:F209-F213

12. Soni A, Pepper G, Wyrwinski P, Ramirez N, Simon R, Pina T, Gruenspan H, Vaca C 1995 Adrenal insufficiency occurring during septic shock: incidence, outcome, and relationship to peripheral cytokine levels. Am J Med 98:266-271

13. Annane D, Bellissant E, Bollaert P, Briegel J, Confalonieri M, De Gaudio R, Keh D, Kupfer Y, Oppert M, Meduri G 2009 Corticosteroids in the treatment of severe sepsis and septic shock in adults: a systematic review. JAMA 301:2362-2375

14. Keh D, Sprung C 2004 Use of corticosteroid therapy in patients with sepsis and septic shock: an evidence based review. Crit Care Med 32:S527-S533

15. Minneci PC, Deans KJ, Eichacker PQ, Natanson C 2009 The effects of steroids during sepsis depends on dose and severity of illness: an updated meta-analysis. Clin Microbiol Infect 15:308-318

16. Marik PE, Pastores SM, Annane D, Meduri GU, Sprung CL, Arlt W, Keh D, Briege J, Beishuizen A, Dimopoulou I, Tsagarakis S, Singer M, Chrousos GP, Zaloga G, Bokhari F, Vogeser M; American College of Critical Care Medicine 2008 Recommendations for the diagnosis and management of corticosteroid insufficiency in critically ill adult patients: consensus statements from an international task force by the American College of Critical Care Medicine. Crit Care Med 36:1937-1949

17. Watterberg KL, Gerdes JS, Cole CH, Aucott SW, Thilo EH, Mammel MC, Couser RJ, Garland JS, Rozycki HH, Leach CL, Backstrom C, Shaffer ML 2004 Prophylaxis of early adrenal insufficiency to prevent bronchopulmonary dysplasia: a multicenter trial. Pediatrics 114:1649-1657

18. Quintos JB, Boney CM 2010 Transient adrenal insufficiency in the premature newborn. Curr Opin Endocrinol Diabetes Obes 17:8-12

19. Fernandez EF, Montman R, Watterberg KL 2008 ACTH and cortisol response to critical illness in term and late preterm newborns. J Perinatol 28:797-802

20. Ng PC, Lam CW, Fok TF, Lee CH, Ma KC, Chan IH, Wong E 2001 Refractory hypotension in preterm infants with adrenocortical insufficiency. Arch Dis Child Fetal Neonatal Ed 84:F122-F124

21. Soliman AT, Taman KH, Rizk MM, Nasr IS, Alrimawy H, Hamido MS 2004 Circulating adrenocorticotropic hormone (ACTH) and cortisol concentration in normal, appropriate-for-gestational-age newborns versus those with sepsis and respiratory distress: cortisol response to low-dose and standard-dose ACTH tests. Metabolism 53:209-214

22. Tantivit P, Subramanian N, Garg M, Ramanathan R, deLemos RA 1999 Low serum cortisol in term newborns with refractory hypotension. J Perinatol 19:352-357

23. Watterberg KL 2004 Adrenocortical function and dysfunction in the fetus and neonate. Semin Neonatol 9:13-21

24. Hart KA, Heusner GL, Norton NA, Barton MH 2009 Hypothalamic-pituitaryadrenal axis assessment in healthy term neonatal foals utilizing a paired low dose/high dose ACTH stimulation test. J Vet Intern Med 23:344-351

25. Silver M, Fowden A 1994 Prepartum adrenocortical maturation in the fetal foal: responses to ACTH. J Endocrinol 142:417-425
26. Silver M, Fowden A, Know J, Ousey J, Franco R, Rossdale P 1987 Sympathoadrenal and other responses to hypoglycaemia in the young foal. J Reprod Fertil Suppl 35:607-614

27. Silver M, Ousey J, Dudan F, Fowden A, Know J, Cash R, Rossdale P 1984 Studies on equine prematurity 2: post natal adrenocortical activity in relation to plasma adrenocorticotrophic hormone and catecholamine levels in term and premature foals. Equine Vet J 16:278-286

28. Cohen ND 1994 Causes of and farm management factors associated with disease and death in foals. J Am Vet Med Assoc 204:1644-1651

29. Hart KA, Slovis NM, Barton MH 2009 Hypothalamic-pituitary-adrenal axis dysfunction in hospitalized neonatal foals. J Vet Intern Med 23:901-912

30. Morris DD, Moore JN 1991 Tumor necrosis factor activity in serum from neonatal foals with presumed septicemia. J Am Vet Med Assoc 199:1584-1589

31. Hart KA, Dirikolu L, Ferguson D, Norton N, Barton M. Daily endogenous cortisol production and hydrocortisone pharmacokinetics in adult horses and neonatal foals. Am J Vet Res in press

32. Briegel J, Kellermann W, Forst H, Haller M, Bittl M, Hoffmann G, Buchler M, Uhl W, Peter K 1994 Low-dose hydrocortisone infusion attenuates the systemic inflammatory response syndrome. The Phospholipase A2 Study Group. Clin Investig 72:782-787

33. Lamberts SW, Bruining HA, de Jong H 1997 Corticosteroid therapy in severe sepsis. N Engl J Med 337:1285-1292

34. Hart KA, Ferguson DC, Heusner GL, Barton MH 2007 Synthetic adrenocorticotropic hormone stimulation tests in healthy neonatal foals. J Vet Intern Med 21:314-321

35. Reimers TJ, Salerno VJ, Lamb SV 1996 Validation and application of solid-phase chemiluminescent immunoassays for diagnosis of endocrine diseases in animals. Comp Haematol Int 6:170-175

36. Singh AK, Jiang Y, White T, Spassova D 1997 Validation of nonradioactive chemiluminescent immunoassay methods for the analysis of thyroxine and cortisol in blood samples obtained from dogs, cats, and horses. J Vet Diagn Invest 9:261-268

37. Donovan DC, Jackson CA, Colahan PT, Norton NN, Clapper JL, Moore JN, Hurley DJ 2007 Assessment of exercise-induced alterations in neutrophil function in horses. Am J Vet Res 68:1198-1204

38. Sun WC, Moore JN, Hurley DJ, Vandenplas ML, Linden J, Cao Z, Murray TF 2008 Adenosine A2A receptor agonists inhibit lipopolysaccharide-induced production of tumor necrosis factor-alpha by equine monocytes. Vet Immunol Immunopathol 121:91-100

39. Figueiredo MD, Salter CE, Andrietti AL, Vandenplas ML, Hurley DJ, Moore JN 2009 Validation of a reliable set of primer pairs for measuring gene expression by real-time quantitative RT-PCR in equine leukocytes. Vet Immunol Immunopathol 131:65-72

40. Figueiredo MD, Vandenplas ML, Hurley DJ, Moore JN 2009 Differential induction of MyD88- and TRIF-dependent pathways in equine monocytes by Toll-like receptor agonists. Vet Immunol Immunopathol 127:125-134

41. Heller AR, Heller SC, Borkenstein A, Stehr SN, Koch T 2003 Modulation of host defense by hydrocortisone in stress dose during endotoxemia. Intensive Care Med 29:1456-1463

42. Keh D, Boehnke T, Weber-Cartens S, Schulz C, Ahlers O, Bercker S, Volk H-D, Doecke W-D, Falke K, Gerlach H 2003 Immunologic and hemodynamic effects of "low-dose" hydrocortisone in septic shock. Am J Respir Crit Care Med 167:512-520

43. Kaufmann I, Briegel J, Schliephake F, Hoelzl A, Chouker A, Hummel T, Schelling G, Thiel M 2008 Stress doses of hydrocortisone in septic shock: beneficial effects on opsonization-dependent neutrophil functions. Intensive Care Med 34:344-349

44. Briegel J, Forst H, Haller M, Schelling G, Kilger E, Kuprat G, Hemmer B, Hummel T, Lenhart A, Heyduck M, Stoll C, Peter K 1999 Stress doses of hydrocortisone reverse hyperdynamic septic shock: a prospective, randomized double-blind single center study. Crit Care Med 27:723-732 